\title{
Bem-estar Subjetivo da População Assistida Pela Estratégia de Saúde da Família do Bairro Residência, Vassouras-RJ
}

\author{
Isabel Cristina Rocha Barbosa \\ Hospital Eufrásia Teixeira Leite, Asilo Barão do Amparo, \\ icrbarbosa@gmail.com \\ Fátima Niemeyer da Rocha \\ Universidade Severino Sombra, CECS/CELCSAH, \\ fatimaniemeyer@uol.com.br
}

\begin{abstract}
Resumo: A felicidade, considerada como principal motivação da vida, instigou pesquisadores da Psicologia Positiva a procurar compreender as razões que fazem algumas pessoas serem mais felizes que outras, buscando entender como, através do exercício de recursos físicos, o indivíduo pode aumentar sua capacidade para intensificar as sensações de satisfação, de alegria e otimismo, objetivando melhorar a qualidade de seu bem-estar. Durante o Estágio Especifico, realizado no posto de Estratégia de Saúde da Família do bairro Residência, em Vassouras, foram observadas famílias que estão inseridas num contexto social menos favorecido, durante a realização de atividades sociais e na dinâmica familiar desta população. Estas observações ofereceram informações significativas sobre o processo de construção da felicidade e sobre a maneira com que suas emoções orientam sua atuação na vida cotidiana, onde uma multiplicidade de critérios são considerados na intenção de alterar positivamente a qualidade de vida dessas pessoas.
\end{abstract}

Palavras-chave: Psicologia Positiva. Bem-estar Subjetivo. Felicidade. Satisfação.

\section{Subjective Well-Being of the Population Assisted by Family Health Center Strategy for The Residence District, Vassouras-RJ}

\begin{abstract}
Happiness, considered as the main motivation in life, urged the Positive Psychology researchers to understand the reasons that make some people happier than others, seeking to understand how, through the exercise of
\end{abstract}


physical resources, the individual may increase its ability to enhance the feelings of satisfaction, of joy and optimism, to improve the quality of their well-being. During the Stage, held at the Family Health Center Strategy for the Residencia District in Vassouras, families who were observed, and are inserted in a social context less favored, during the conduct of social activities and family dynamics of this population. These observations provide significant information about the process of building the happiness and the way in which their emotions guide their actions in everyday life, where a number of criteria are considered in order to positively change the quality of life of these people.

Keywords: Positive Psychology. Subjective Well-being. Happiness. Satisfaction.

\section{Introdução}

Ao longo da história, a busca pela felicidade sempre esteve permeando as reflexões de filósofos e pensadores. Considerada como o significado e a principal motivação da vida, a felicidade só alcançou seu status de tema significativo de investigação na ciência em meados do século XX, com os pesquisadores da Psicologia Positiva que, interessados em compreender as emoções positivas, procuraram entender as razões que motivam maiores índices de alegria e otimismo nas pessoas. Ao definir bem-estar o indivíduo pode ser influenciado por diversas variáveis, tais como idade, gênero, nível socioeconômico e cultural, entre outras. Porém é possível dizer que o bem-estar subjetivo é uma atitude e, como tal, possui pelo menos dois componentes básicos que são: a cognição, que se refere aos aspectos intelectuais, e o afeto, que pode ser tanto positivo quanto negativo.

Durante o desenvolvimento das atividades do Estágio Supersivionado Específico do Curso de Psicologia da Universidade Severino Sombra, realizado no posto de Estratégia de Saúde da Família do bairro Residência, em Vassouras, o contato com as famílias locais que estão inseridas num contexto social menos favorecido possibilitou realizar observações das atividades sociais e da dinâmica familiar desta população, atentando para os padrões de comportamento aprendido que se repetem na condução de suas vidas, refletindo o processo de desenvolvimento emocional e suas representações. Essas observações, interpretadas à luz dos estudos em Psicologia Positiva, motivaram a realização deste trabalho, o qual pretendeu compreender a percepção das pessoas quanto à satisfação e ao bem-estar, quando inseridas num ambiente pouco gratificante, salientando a forma de construção emocional desses indivíduos e a maneira com que desenvolvem habilidades a fim de atingir um nível mais alto e sustentável de bem-estar, objetivando a orientação para um processo de transformação e, consequentemente, a possibilidade de aumentar a qualidade de suas vidas. 
(publicações de textos, ensaios e artigos de discentes)

\section{Psicologia Positiva}

A Psicologia Positiva está voltada para o estudo da emoção positiva, dos traços positivos da personalidade, das habilidades (como inteligência e capacidade atlética) e das forças e virtudes, as quais, reconhecidas e exercitadas, possibilitam uma maior realização e prazer na vida (Seligman, 2004). De modo geral, os estudos revelam três aspectos na construção da felicidade: a) "estar no controle de sua vida" (Csikszentmihalyi, 1999, Ryff, 1989; Ryff e Keyes, 1995); b) estado (Diener, 1984, 1996; Michalos, 1980); c) traço (Diener, 1984, 1996; Michalos, 1980).

Do filósofo grego Aristóteles, que escreveu que a felicidade "é uma expressão da alma em determinadas ações", ao pai da psicanálise, Sigmund Freud, que observou ser a felicidade uma questão de amar e trabalhar, encontramos, ao longo da história, inúmeras reflexões acerca da ideia de felicidade (Lyubomirsky, 2008). Segundo Seligman (2004), durante a segunda metade do século XX a Psicologia voltou sua atenção para a doença, os distúrbios, proporcionando grande avanço no conhecimento dos transtornos que se desenvolvem ao longo da vida. No final do século XX, pesquisadores na área das ciências sociais voltaram suas investigações para o campo da felicidade e, embora seja um tema que foi alvo de especulação de alguns filósofos desde séculos passados, a felicidade, o bem-estar subjetivo, a satisfação com a vida, se colocam como tópicos importantes de estudos científicos na busca de qualidade de vida (Myers e Diener, 1997).

A vida biológica é um processo automático, desde que as necessidades básicas para nossa sobrevivência sejam atendidas; mas viver plenamente requer empenho no controle dos fenômenos integrados para nos proporcionar bem-estar e prazer, impedindo que fatores externos sejam os condutores da nossa direção (Csikszentmihalyi, 1999). Embora a vida plena seja, em parte, determinada pelos processos químicos do nosso corpo e pela interação biológica entre os órgãos, fundamentalmente será também determinada pelos pensamentos, emoções e interpretações que damos aos fenômenos químicos, biológicos e sociais (Csikszentmihalyi, 1999). Contudo, ressaltam Diener e Lucas (1999), o bem-estar subjetivo se estabelece através da avaliação tanto cognitiva quanto emocional da própria existência.

Teorias e pesquisas envolvendo felicidade e bem-estar subjetivo refletem uma multiplicidade de critérios e de indicadores, mas ainda é difícil estabelecer as diferentes variáveis relacionadas à qualidade de vida, ou seja, o grau de importância de cada uma, suas inter-relações e a direção de causalidade entre elas. Lyubomirsky (2008) diz que ao tornar-se mais feliz o indivíduo não apenas aumenta as experiências de alegria, mas também os níveis de energia, sistema imonulógico e relações sociais, sustentando sentimentos de auto-estima e autoconfiança.

\section{Bem-estar Subjetivo}

Diener, Oishi e Lucas (2003) relacionam o bem-estar subjetivo com o que as pessoas leigas chamam de felicidade, prazer ou satisfação. Larson (2000) refere-se à felicidade também como afeto positivo e afeto negativo, ligado à atenção social, a sensação agradável de satisfação ou desprazer. Embora publicações sobre conceitos de felicidade não cheguem 
a um consenso, Csikszentmihalyi (1999) afirma que a verdadeira felicidade seria aquela que se seguiria ao flow (o fluxo, o fluir), que corresponde à sensação de ação sem esforço, característica de momentos excepcionais na vida de uma pessoa. O bem-estar subjetivo, no entanto, estaria ligado a autovalorização por realizações pessoalmente julgadas importantes, independentemente de recompensas externas, ou seja, algo resultante da maneira como o indivíduo interpreta os acontecimentos em sua vida e da aprendizagem no controle de suas vivências interiores (Csikszentmihalyi, 1992).

Csikszentmihalyi (1992) salienta o fazer acontecer, o empenho máximo do indivíduo em se esforçar para realizar algo difícil e que vale a pena. Seria a experiência intensa de alegria - incluindo prazeres sensuais ou sexuais - e vivências flow, envolvendo um mergulho intenso e entrega a uma atividade prazerosa. Para Seligman (2004), de modo geral, não existem maneiras espetaculares e rápidas para se alcançar o bem-estar subjetivo ou a felicidade; existem, na verdade, diversos recursos pessoais que podem ser exercitados, promovendo e desenvolvendo sentimentos positivos e duradouros - e não apenas seriam indicadores as características da personalidade.

\section{Felicidade construída - estar no controle de sua vida}

Estudos realizados tanto por Csikszentmihalyi (1992) quanto por Ryff e Keyes (1995) sugerem, com o conceito de "felicidade aprendida", que se compreendidos os mecanismos que possibilitam as sensações de satisfação e felicidade, todo indivíduo é capaz de produzir esse estado de forma objetiva, construindo o próprio bem-estar.

A felicidade, na realidade, é um estado que precisa ser preparado, cultivado e defendido por nós. As pessoas que aprendem a controlar sua vivência interior serão capazes de determinar a qualidade de suas vidas; isso é o mais próximo que qualquer um de nós consegue chegar do estado de felicidade (Csikszentmihalyi, 1992 p.14).

Ao longo do desenvolvimento humano, através das percepções diante da vida, vários orientadores internos vão se formando, vão sendo construídos pelas forças que dão forma às experiências, cada qual provocando um impacto sobre as sensações boas ou más e, em sua maioria, inerentes ao controle pessoal (Csikszentmihalyi, 1992).

Seligman (2004) fala em emoções positivas e negativas como construtores cognitivos determinantes no estabelecimento da qualidade de vida. Ligados aos bons e maus momentos, a vida vai sendo moldada por virtudes como bondade, generosidade, lealdade e, em contrapartida, por emoções como o medo, a raiva e a tristeza. Identificar e intensificar forças e virtudes, visando proporcionar ao indivíduo encontrar o nicho onde possa exercitar ao máximo sua capacidade de construção afetiva, aumenta sua condição de adaptação levando-o a alcançar satisfação. 
(publicações de textos, ensaios e artigos de discentes)

\section{Felicidade enquanto estado}

De acordo com Feist et al (1995), estar feliz implica muitos momentos de felicidade na vida e seria uma forma de percepção de bem-estar fundamentada na experiência com o mundo. As teorias denominadas Bottom-Up do bem-estar subjetivo, relacionadas aos fatores extrínsecos ao indivíduo, ou seja, às influências situacionais, apontam para a ideia de que a felicidade é simplesmente a soma de vários pequenos prazeres; parte do modo como a pessoa julga se sua vida é feliz, ao utilizar alguns cálculos mentais para fazer o balanço entre os prazeres e os sofrimentos. Uma vida feliz, neste ponto de vista, é meramente um acúmulo de momentos felizes (Diener, 1984).

Glatzer (1987) afirma ser a felicidade concebida como um estado emocional produzido por eventos positivos e negativos, relacionados às experiências vivenciadas. E Diener (1996) salientou que tanto circunstâncias ambientais como fatores ligados à personalidade podem produzir mudanças significativas no bem-estar subjetivo, desde que ocorram de maneira abundante e duradoura. Baseado na teoria da adaptação, de que existem padrões afetivos derivados da própria existência do sujeito, Diener (1984) ressalta que esses padrões podem ser alterados para cima ou para baixo por qualquer circunstância. Reforçando as teorias Top-Down do bem-estar subjetivo, relacionadas aos fatores intrínsecos do indivíduo, que assumem haver uma predisposição global para interpretar as situações e as experiências de vida de um modo positivo, e que essa propensão influencia as interações que o indivíduo tem com o mundo, Suh, Diener e Fujita (1996) colocam que novos eventos trariam novas informações, que passam a ter prioridade sobre os eventos anteriores.

\section{Felicidade enquanto traço}

Observações realizadas por Seligman (2004) sobre felicidade relacionam traços da personalidade como fatores promissores para o bem-estar subjetivo; além disso, afirma que indivíduos com laços sociais fortes são mais satisfeitos e seus sentidos de julgamento se desenvolvem para um sentimento geral de bem-estar, o que ele chama de inteligência social, fator que ajuda o indivíduo a moldar a vida ao redor dele. Para Seligman (2008), ao contrário dos estados, os traços são características positivas ou negativas que se repetem, independentemente das ocasiões e situações, ou seja, são disposições permanentes cujo exercício torna mais prováveis os sentimentos passageiros. Diener e Seligman (2004) observaram que o sistema emocional de pessoas muito felizes reage de maneira apropriada às circunstâncias da vida cotidiana, o que sugere ser determinante a predisposição para interpretar as experiências da vida de forma positiva, independente dessas serem boas ou más.

Segundo Feist et al. (1995) a mente seria uma intérprete ativa e organizadora de toda a experiência sensorial do sujeito, filtrando toda informação que chega a ela de maneira coerente com suas crenças e atitudes, apontando para a visão das teorias Top-Down. Já Suh, Diener e Fujita (1996) revelam em seus estudos que as pessoas reagem de maneira positiva a eventos da vida ou mudanças apenas por um curto período, retornando à linha de base estável determinada por sua personalidade. 
(publicações de textos, ensaios e artigos de discentes)

\section{Personalidade e Temperamento}

Diener (1984) e Diener e Lucas (1999) revelam que a personalidade predispõe o bemestar subjetivo, influenciando a satisfação do indivíduo e os sentimentos dele com relação aos domínios específicos da vida. E Diener, Suh, Oishi (1997) sugerem que a intensidade emocional (tanto para as emoções agradáveis quanto para as desagradáveis) pode influenciar a qualidade da felicidade e que o otimismo, a autoestima e a extroversão são características de personalidade em geral presentes em pessoas felizes, salientando assim, o temperamento como condutor de comportamentos diretamente relacionados ao bem-estar subjetivo.

\section{Religiosidade}

Estudos analisados por Myers e Diener (1997), indicam que a felicidade e a satisfação da vida se elevam significativamente como resultado da afiliação e da frequência religiosas e pela entrega a essas crenças, principalmente, entre pessoas idosas. Ainda sugerem, em relação à fé e a capacidade de lidar com uma crise, que pessoas que têm fé recuperam o nível de felicidade com mais facilidade após sofrer separação, desemprego ou doença grave. Esclarecem também que ligações positivas entre a fé e o bem-estar incluem os relacionamentos próximos de suporte mais procurados por pessoas ativas em suas comunidades de fé, no sentido do significado e da finalidade que muitas pessoas derivam de sua fé e da motivação para focalizar além do seu próprio self. Uma visão espiritual do mundo pode oferecer respostas às perguntas mais profundas da vida e uma avaliação otimista dos eventos de vida.

\section{Componentes do Bem-Estar Subjetivo}

A Psicologia Positiva aponta para o caminho da compreensão do que nos move, do que faz algumas pessoas encontrarem maior significado em suas vidas do que outras, e busca identificar e aperfeiçoar as forças fundamentais a serem utilizadas no propósito de desenvolver habilidades emocionais no indivíduo, para a realização mais duradoura em sua vida, mesmo em condições adversas (Seligman e Csikszentmihalyi, 2000). Segundo Glatzer (1987) a satisfação com a vida, o afeto positivo e o afeto negativo são considerados componentes significativos para o bem-estar subjetivo. E o nível de satisfação pode ser o modulador das emoções, podendo aumentar ou diminuir, tendo como base o pensamento (Diener, Suh e Oishi, 1997).

Csikszentmihalyi (1992) afirma que a experiência máxima de bem-estar depende da capacidade de controle da consciência organizada de maneira harmoniosa e dos esforços criativos individuais, combinando oportunidades de ação e investimento de energia psíquica. Para Seligman (2004) é necessário o desenvolvimento de forças e virtudes, exercitando sentimentos positivos que irão proporcionar gratificação, integrando valores e produzindo base na autenticidade para a felicidade, ou seja, dar significado à vida promovendo satisfação no exercício da vida diária.

As forças pessoais, segundo Seligman (2004), podem ser tônicas, como a bondade, a 
lealdade e a espiritualidade, aspecto da introversão do sujeito (com base na atividade elétrica muscular em repouso) ou fásicas, como a perspectiva, a justiça e a coragem, considerando como o indivíduo irá reagir diante de um desafio (com base na atividade elétrica muscular contraída). Acredita serem essas forças pessoais as responsáveis pelo sucesso na vida e, concretamente, o fator determinante da mais profunda satisfação emocional. Algumas dessas forças, apresentadas em suas pesquisas, são típicas da personalidade e outras não, sendo desnecessário o esforço na correção das fraquezas, pois na verdade o investimento deve ser direcionado para dar significado e propósito à vida - trata-se de aderir a algo maior, de maior significado para os aspectos que constituem a felicidade e a possibilidade de intensificar essa emoção.

De acordo com Seligman (2004) sentimentos são ocorrências momentâneas que não precisam ser aspectos recorrentes da personalidade. Sentimentos positivos, como satisfação, felicidade e esperança provocam aproximação em relação a qualquer objeto, enquanto sentimentos negativos como medo, raiva e tristeza, provocam afastamento. Desde a teoria da evolução, a psicologia trabalhava as emoções negativas como responsáveis por um comportamento de desistência, sendo elas, normalmente, evocadas por ameaças externas que mobilizavam o indivíduo para eliminar situações aversivas. Tendo em vista que o universo não foi criado para atender às nossas necessidades, a frustração é um componente intrínseco à condição humana e sempre que uma necessidade é satisfeita imediatamente passamos a querer mais (Csikszentmihalyi, 1992).

Compreendendo a realidade do cotidiano, com as exigências e frustrações que possam surgir, cada indivíduo percebe, através dos sentidos, o conteúdo específico das suas experiências de vida que irão proporcionar uma noção bastante clara a respeito de seus próprios limites (Csikszentmihalyi, 1999). Diener (1984), ao expor as condições que influenciam a satisfação, diz que este julgamento está relacionado mais amplamente ao bem-estar subjetivo do que com condições objetivas e aponta para a correlação entre a satisfação e o self, sugerindo que as pessoas com autoestima mais elevada possuem um padrão de vida e convivência familiar mais satisfatório, precedendo aos sentimentos positivos. Para Csikszentmihalyi (1992) a consciência, onde a realidade é vivenciada de forma subjetiva, funciona como uma central informativa que processa e estabelece prioridades entre diversos dados e desenvolve a capacidade de organização para adquirir controle sobre as emoções e pensamentos, proporcionando ao indivíduo o meio para ser bem-sucedido e ter mais prazer na vida.

\section{Satisfação}

A satisfação caracteriza-se pelo movimento em busca de uma sensação de realização. É um processo de julgamento em que o próprio indivíduo avalia, de maneira global, sua qualidade de vida, partindo de critérios pessoais comparados a padrões que ele mesmo determinou, a fim de obter satisfação pessoal. (Diener e Emmons, 1985) Wong (1989) afirma que preencher a existência de significado tem vários efeitos positivos que levam a satisfação pessoal, e elaborou uma síntese envolvendo esses diversos componentes: "significado pessoal é um sistema cognitivo construído individualmente, isto é, que é fundamentado em valores e é capaz de dotar a vida de satisfação pessoal” (p.517). Essa 
avaliação examina aspectos tanto bons quanto ruins da vida do sujeito e privilegia as expectativas estabelecidas por ele mesmo comparadas a acontecimentos agradáveis que proporcionaram uma sensação inesperada de maior realização, mais intensas que a sensação de prazer atingida pelos programas biológicos ou pelo condicionamento social, reduzindo o desequilíbrio fisiológico (Cikszentmihalyi, 1992).

Seligman (2004) evidencia que tanto a emoção comanda o pensamento, quanto o pensamento é modificado pelo estado emocional. Diferentemente, a visão freudiana afirma que a emoção comanda os conteúdos do pensamento e que forças do passado irão dirigir significativamente a vida do sujeito. No entanto, Seligman (2004), afirma ser indispensável compreender que a interpretação do indivíduo a respeito de suas próprias vivências irá determinar a maneira com que suas emoções conduzirão seus pensamentos, e que o fortalecimento de recursos pessoais concretamente poderá modificar a qualidade de vida do sujeito e suas relações. Refletindo sobre a satisfação como um acontecimento que pode se expandir, tornando o self mais complexo em alguns aspectos, o indivíduo constrói, através de suas experiências positivas, a possibilidade de estar no controle de sua própria vida e transformar atividades do cotidiano em algo muito mais gratificante que irá propiciar a experiência do fluir (Cikszentmihalyi, 1992).

\section{Adaptação Hedonista}

Aconcepção de desenvolvimento humano, apesar da predominância do modelo biomédico, considerada pela Psicologia do Desenvolvimento, revela que esse processo é tanto cumulativo quanto inovativo, o que ressalta que todo o indivíduo sofre permanentemente transformações ao longo da vida. Consequentemente, mudanças irão ocorrer, significando tanto perdas quanto ganhos, e todo indivíduo é capaz de se adaptar mediante suas condições e experiências anteriores (Baltes, 1987).

Embora seja constante a busca pela felicidade, cada indivíduo se empenha ao máximo para tornar possíveis mudanças favoráveis no casamento, habitação, bens, beleza física, como condição para obter o que acredita ser felicidade (Lyubomirsky, 2008). Partindo deste pressuposto seria plausível pensar que pessoas que possuem uma vida mais afortunada que as outras seriam, então, mais felizes e realizadas. No entanto, estudos demonstram que embora realizações importantes tenham o poder de aumentar a felicidade, isso ocorre apenas por um curto espaço de tempo. O obstáculo ao aumento do nível de felicidade é a capacidade do próprio ser humano se adaptar rapidamente a condições inesperadas de mudanças, tanto sensoriais como fisiológicas, chamadas de adaptação hedonista (Seligman, 2004). Este fenômeno ocorre em todos os âmbitos da vida, apenas limitado por alguns acontecimentos ruins, como o luto de uma mãe que perde o filho ou a perda de um ente querido de maneira trágica (Seligman, 2004). Lyubomirsky (2008) revela que este mesmo fenômeno é responsável pela modificação de acontecimentos positivos, levando o sujeito à acomodação da sensação de felicidade temporária, retornando ao nível normal. 
(publicações de textos, ensaios e artigos de discentes)

\section{Consciência - o que a ordena}

A consciência tem por função representar toda a informação que ocorre dentro e fora do organismo, levando o indivíduo a avaliar os estímulos e a agir de modo correspondente. Nesse sentido, o processamento das sensações, das percepções, sentimentos e ideias se estabelecem como numa central informativa, permitindo ao indivíduo, além do acesso aos dados existentes, criar ou reinventar ideias (Csikszentmihalyi, 1992). "A qualidade de ser consciente [...] permanece sendo a única luz que ilumina nosso caminho e nos conduz através da obscuridade da vida mental" (Freud, 1974, p.28).

$\mathrm{Na}$ linha da evolução, o sistema nervoso foi-se tornando tão complexo que hoje exibe, até certo ponto, a capacidade de mudar os conteúdos da consciência, contrariando sua programação genética e do ambiente objetivo (Csikszentmihalyi, 1992). Logo, a capacidade de recriar que a consciência permite ao indivíduo é o aparato principal na possibilidade da construção de recursos físicos para lidar com acontecimentos desagradáveis que possam ocorrer em suas vidas (Seligman, 2004). O desenvolvimento dessa característica da consciência vai depender da maneira que as informações forem nela organizadas - a intenção - e, principalmente, da possibilidade do sujeito adquirir controle sobre as próprias emoções e pensamentos. A intensão é uma unidade da informação, criada pela necessidade biológica ou metas sociais internalizadas voltadas para realizar um desejo. E, como a consciência corresponde à realidade vivenciada de forma subjetiva, permite ao indivíduo a liberdade de controle e conhecimento de suas reais experiências, dando a ele a capacidade de focalizar sua atenção conforme suas necessidades para atingir metas (Csikszentmihalyi, 1992). A atenção, por sua estrutura flexível, pode ser investida de várias maneiras que possibilitam tornar a vida feliz, pela riqueza de conteúdos, aprendendo a administrar as próprias metas, ou infeliz, pelo direcionamento da energia investida negativamente. Dessa forma, cada indivíduo cria a si mesmo através da energia psíquica investida, moldado pela maneira que a utiliza (Csikszentmihalyi, 1992).

Essa ordem no processamento de energia psíquica mobiliza todo o organismo em um modo de aproximação ou evitação, direcionando o foco principal da atenção na busca de qualidade na experiência, evidenciando que emoções, intenções e pensamentos não atravessam a consciência como elementos distintos de experiência, mas que estão constantemente interconectados e se modificam uns aos outros à medida que avançam e, naturalmente, fortalecendo e integrando o self, por ser o elemento que representa simbolicamente todos os conteúdos da consciência no sistema que predomina a causalidade. Permite, assim, ao indivíduo a experiência de harmonia do fluir, porque neste estado de profunda concentração a mente está organizada de maneira extraordinária (Csikszentmihalyi, 1999).

\section{Qualidade de vida - o que determina essa construção}

A qualidade de vida percebida é totalmente subjetiva e está diretamente relacionada com a avaliação particular do indivíduo de seu contexto familiar e social, sua saúde física, o uso de seu tempo (de que forma este é investido) e suas condições de moradia (Diogo, Néri e Cachioni, 2004). O modo como é investido o tempo e a energia psíquica aplicados para a manutenção da vida do indivíduo, será determinante no desenvolvimento do potencial 
para seu crescimento pessoal. O que é feito para gerar energia para a própria sobrevivência, desde atividades produtivas até atividades de manutenção, quase nunca é ideal, pois o que sobra de tempo é muito pouco para a realização de atividades de lazer que auxiliam na obtenção de uma vida mais plena em sua essência (Csikszentmihalyi, 1999).

Segundo Maslow (Davidoff, 2004) as necessidades fisiológicas precisam ser satisfeitas para que se possa buscar atender as necessidades de segurança e, por consequência, permite o seguimento para as necessidades sociais, que se saciadas abrem espaço para as necessidades de autoestima. Se uma destas necessidades não está saciada há uma incongruência, mas quando todas estiverem atendidas abre-se espaço para a autorealização, que é um aspecto de felicidade do indivíduo. Embora a condição humana seja dependente das necessidades básicas de sobrevivência, não somente elas irão determinar a qualidade de vida do sujeito. A casualidade do nascimento irá proporcionar ao indivíduo um manancial de informações que, interpretadas de maneira singular, oferece o conteúdo específico da experiência. Assim também, na questão da individualidade, as categorias socioculturais e as circuntâncias, atreladas a iniciativa pessoal, permitirão ao indivíduo os recursos que irão determinar sua qualidade de vida (Csikszentmihalyi, 1999).

"Um estado de espírito positivo nos induz a um modo de pensar completamente diferente de um estado de espírito negativo" (Seligman, 2004). Segundo Lyulomirsky (2008), as pessoas felizes tendem a armazenar informações de acontecimentos positivos em maior número que acontecimentos negativos, além de serem mais satisfeitas no casamento, no trabalho, na vida social e apresentarem o sistema imunológico mais fortalecido. Em contrapartida, Seligman (2004) ressalta que pessoas deprimidas são mais precisas e realistas quanto às suas habilidades, mais espertas; enquanto as mais felizes supervalorizam sua capacidade.

Consideravelmente, as emoções positivas são um importante recurso na prevenção e manutenção da saúde física e mental do indivíduo. Várias pesquisas, como de Seligman (2004), forneceram informações significativas no que implica a melhoria da saúde, com melhores hábitos, e no prolongamento da vida, revelando que pessoas otimistas têm maior suporte na construção de recursos físicos, proporcionados pela maneira com que lidam com situações adversas. $\mathrm{Na}$ esperança equivocada de que a mudança das circunstâncias proporcionará felicidade, as pessoas acreditam que beleza, sucesso profissional e material são os fatores essenciais para a realização de todos os seus anseios. Sem dúvida, as pesquisas sugerem que esses são fatores incentivadores da felicidade, mas não existem evidências associativas para que ela ocorra. Os seres humanos acostumam-se rapidamente a mudanças sensoriais ou fisiológicas - é o fenômeno da adaptação hedonista - e, consequentemente, a alteração emocional provocada pelas tranformações ocorridas em sua vida, em curto espaço de tempo, tende a se acomodar, levando o sujeito ao seu nível basal de felicidade (Lyubomirsky, 2008).

São duas as estratégias que podem ser adotadas para melhorar a qualidade de vida: a primeira, fazendo com que as condições externas se adaptem às metas da pessoa; e a segunda, alterando o modo como são vivenciadas as experiências externas para adaptálas às suas metas; porém nenhuma delas será eficiente separadamente. O essencial é como a pessoa se sente a respeito dela mesma e do que acontece em seu dia a dia 
(Csikszentmihalyi, 1992).

Considerando o tipo de experiência que faz a vida melhor, o prazer é um importante componente da qualidade de vida, devolvendo ordem à consciência quando as necessidades do corpo se impõem e provocam a desordem psíquica (ou entropia psíquica). Numa outra categoria está a satisfação, caracterizada pelo movimento, pela sensação de realização, pela gratificação por algo alcançado de maneira não programada. (Csikszentmihalyi, 1992) Para Csikszentmihalyi (1999) o que diz respeito à vida cotidiana não pode ser definido apenas pelo que a pessoa faz, mas devem ser também consideradas as suas relações com os outros e os atos e pensamentos influenciados por eles, estando presentes ou não. A qualidade a que se refere está no equilíbrio de vários fatores: na satisfação que pessoalmente seja importante para o indivíduo, no viver com o suficiente para suprir suas necessidades reais de consumo, valorizando todas as suas experiências, como o que existe de mais digno, sentindo-se recompensado por gostar efetivamente do que faz sem esperar por recompensas externas, desenvolvendo o que se chama personalidade autotélica . Revela, ainda, que por mais individualista que seja uma cultura, os outros ainda determinam significativamente a qualidade de vida de um indivíduo.

\section{Bem-Estar Subjetivo da População Assistida no posto de Estratégia de Saúde da Família do Bairro Residência de Vassouras, RJ}

O contato com as famílias do Bairro Residência, em Vassouras, durante o desenvolvimento das atividades do Estágio Supervisionado Específico do Curso de Psicologia, realizado no posto de Estratégia de Saúde da Família, proporcionou a oportunidade de observação, em que foram verificados padrões repetidos de comportamentos e de dinâmica familiar, favorecendo a avaliação da realidade socioeconômica e cultural desses indivíduos. Os atendimentos domiciliares, propostos pelo projeto de Saúde Pública, para trabalhar a prevenção de doenças, permitiram o estreitamento das relações entre profissionais e pacientes dentro de seu contexto de vida. Com base nas teorias e estudos da Psicologia Positiva, foi possível salientar que, no processo de desenvolvimento dos indivíduos dos grupos acompanhados, os padrões de personalidade, os comportamentos e as atitudes diante da vida são determinantes para caracterizar a repetição na formação das estruturas que permitem tanto a construção da felicidade quanto da qualidade de vida das pessoas em situações adversas.

A população assistida durante o estágio está inserida num contexto social menos favorecido, o que denota significativa dificuldade tanto econômica quanto cultural de serem utilizadas como suporte externo para garantir mudanças de perspectivas do indivíduo, mesmo em relação a novas gerações. Partindo dos pressupostos de Maslow, que aponta para o equilíbrio do organismo como resultado de um funcionamento satisfatório quando atendidas suas necessidades básicas, observa-se um nível variável de atendimento de necessidades, tendo em vista a realidade da pessoa com baixa expectativa de ganhos e mudanças, isso se considerado como fator para aumentar os níveis de qualidade de vida.

Os locais onde são construídas as moradias são, em sua maioria, pequenos lotes de um mesmo terreno, cedidos aos componentes da família à medida que estes constituem seu 
próprio núcleo familiar. Geralmente, são construções inacabadas que oferecem pouco conforto e segurança, com um número reduzido de cômodos, onde os moradores se acomodam sem qualquer privacidade e/ou individualidade. As pessoas se mostram, muitas vezes, solidárias e acolhedoras, sendo prática comum abrigar amigos em seus lares, apesar da dificuldade financeira para a manutenção do grupo.

Os filhos, em geral, dividem a mesma cama e os objetos pessoais são compartilhados; em alguns casos, mesmo quando se trata de material escolar, é comum que irmãos se alternem no uso dos referidos objetos. A gravidez na adolescência é significativamente grande, sendo comum ocorrerem várias gestações em um curto espaço de tempo, onde o cuidador, geralmente, é a avó. As famílias são numerosas e, em sua maioria, se apresentam como monoparentais, sendo também comum no mesmo núcleo a ocorrência de várias uniões maritais consecutivas.

Quanto aos comportamentos sociais observáveis, é comum o uso frequente de álcool e, em alguns casos, também o uso de outras drogas. Com referência à renda familiar, poucos indivíduos possuem trabalho fixo, geralmente vivendo de serviços temporários. A manutenção dessas famílias, no que se refere à alimentação e serviços básicos essenciais (luz e água) é, principalmente, responsabilidade do idoso pensionista, sendo bastante comum serem esses idosos os veículos para o atendimento familiar, por produzirem com frequência doenças como depressão, hipertensão e diabete, ao enfrentarem situações que geram ansiedade, levando-os, muitas vezes, a utilizar a medicalização como suporte para realizar suas atividades cotidianas. No entanto, não em menor número, existem casos de idosos que, contrariando o modelo biomédico em relação ao envelhecimento, mesmo em condições financeiras pouco favoráveis, insistem na boa longevidade em domínios da saúde física e mental, e se apresentam como o alicerce do grupo familiar para a condução de suas vidas.

Csikszentmihalyi (1999) fala sobre o processo automático da vida biológica, das necessidades de sobrevivência atendidas e dos processos psíquicos, relacionando-os ao bem-estar subjetivo. Partindo deste suposto, desde que mantidas as condições básicas de subexistência do organismo, todo indivíduo torna-se igualmente capaz de tornar sua vida plena, tendo como organizador o controle sobre suas emoções, pensamentos e a interpretação de suas experiências. Considerando a realidade de indivíduos que enfrentam adversidades e relacionando as circunstâncias a que estão sujeitos com a experiência sensorial que, juntas, irão compor sua personalidade, pode-se notar a influência das informações determinando as características de suas estratégias pessoais, como orientadoras das vivências internas e externas. Portanto, ao ser considerado ineficiente o atendimento dessas pessoas, quanto às suas necessidades básicas de sobrevivência, somado a pouca gratificação e o sentimento de inadequação social, torna-se importante a probabilidade do indivíduo em ser disfuncional na interpretação e controle dos conteúdos de sua consciência e na utilização desses como agentes organizadores e transformadores dos dados que conduzem pensamentos e emoções.

Quando Seligman (2004) afirma que ao reconhecer e exercitar a capacidade pessoal é possível fortalecer emoções positivas na construção da felicidade, sugere que a interpretação das experiências externas e a carga genética exercitadas são as responsáveis por tornar 
funcional o indivíduo, podendo modificar de maneira criativa sua vida. Durante a infância, o indivíduo já apresenta traços de personalidade geneticamente determinados compondo seu temperamento, mas esses traços também são moldados por sua interação com os pais. No decorrer do seu desenvolvimento, outros componentes serão adicionados dando oportunidade a novas experiências emocionais enquanto seu sistema nervoso está em formação, provocando grande influência na capacidade dessa criança em lidar com suas emoções diante da vida. A criança emocionalmente preparada, cujos pais ou responsáveis vêem na manifestação de suas emoções negativas a oportunidade de orientação, ajudando essa criança a nomear e reconhecer o que sente, tem maior possibilidade de aprender a reagir e a se recuperar de situações de estresse ou frustração, conseguindo controlar as reações negativas de forma mais rápida e tendo mais habilidade em solucionar problemas. Numa realidade onde os papéis de referência e identificação das crianças se confundem é provável uma dificuldade maior de organização consciente que constitui a forma com que esse indivíduo irá lidar com suas próprias emoções e as exigências ocasionais de seu dia a dia.

Demonstrando essa construção no processo de desenvolvimento, ao observar crianças expostas a comportamentos desajustados, salientando a incapacidade do adulto em perceber as próprias emoções, sujeitas a expressões de raiva, agressividade e ridicularização, nota-se que essas crianças tendem ao descontrole pela dificuldade de regular as próprias emoções e pelo sentimento de inadequação, que as orientam para serem rotuladas como deficientes de caráter. A atitude dos responsáveis pela criação de uma criança será refletida na base da sua preparação emocional, estabelecendo a forma dela interagir com o mundo, que será constituída de emoções minimizadas em seu real sentido e disfuncionais na resolução de problemas que poderiam melhorar significativamente sua satisfação e bem-estar na vida. Com base nisso, foram observados comportamentos que se tornaram característicos das pessoas assistidas. É comum a dificuldade de contato visual em várias situações, a rejeição ao toque corporal é significativa e, principalmente, é marcante a desvalorização de manifestação afetiva, por ser considerada como agente manipulador de situações do cotidiano.

A experiência naturalmente promove no indivíduo um manancial de emoções positivas ou negativas que fundamentam a construção de sua personalidade e habilidades que irão auxiliar seu processo de reconhecimento e atuação no mundo. As vivências afetivas, estando diretamente ligadas à condição saudável de aprendizagem, que comprometem substancialmente o comportamento da pessoa ao se relacionar com o meio em que vive, são evidenciadas quando são analisados os desajustes de adolescentes da área assistida, pelo alto índice de evasão escolar, o envolvimento com gangues que promovem brigas anunciadas e o significativo abuso de drogas lícitas e ilícitas. Não são raros os casos de homicídio nesta localidade, geralmente de jovens na faixa de 14 a 25 anos, bem como de pequenos furtos, invasões a domicílios, espancamentos e estupros.

Diener, Oishi e Lucas (2003) relacionam a satisfação e o prazer ao que se considera felicidade, enquanto Larson (1987) reconhece a felicidade como afetos relacionados à atenção social, promovendo sensações de prazer ou desprazer. Dessa forma, questiona-se como obter satisfação em condições precárias de conteúdos de prazer e realização diante 
das dificuldades da vida, mesmo considerando aspectos positivos e negativos das emoções e suas interpretações internas. Opinião semelhante é expressa por Csikszentmihalyi (1992) ao salientar que a satisfação é resultante da interpretação e do controle de suas vivências pessoais e da entrega do indivíduo às atividades prazerosas, condições pouco evidenciadas quando observados os grupos de pouca representatividade social.

Seligman (2004) menciona que a possibilidade de desenvolver recursos pessoais para obtenção de bem-estar subjetivo e sentimentos duradouros torna real a avaliação das forças individuais a serem potencialmente desenvolvidas para constituir a felicidade das pessoas, apesar da realidade social ser pouco gratificante. Observa-se, nesse grupo de famílias, que as experiências de alegria estão relacionadas à frequentes encontros sexuais sem vínculos significativos, tornando esses prazeres o mecanismo propulsor no exercício de busca da felicidade e de realização pessoal. A isso se refere Csikszentmihalyi (1992) quanto à experiência do fluir em atividades prazerosas e na construção do bem-estar subjetivo pela capacidade individual de produzir satisfação, determinando a qualidade de suas vivências, independentemente de firmes laços afetivos. Embora comparados a estes estudos, os grupos assistidos revelam que constituem a experiência do fluir, de satisfação, ligada apenas a ocasiões de atividade sexual, como fator de aproximação à condição de indivíduos de classes sociais mais favorecidas.

Cada pessoa apreende as informações vivenciais de maneira singular; mesmo exposta a elas ao mesmo tempo no mesmo círculo familiar, as representações são estabelecidas como orientadores internos. Baseado nessa forma de construção pode-se observar vários integrantes do mesmo grupo com diferentes mecanismos de execução de habilidades ao utilizar as forças e virtudes que determinam a qualidade de vida. Seligman (2004) fala dessa construção e do impacto causado por sensações boas ou más inerentes ao controle pessoal, o que permite ver que em indivíduos do mesmo grupo a manifestação do que eles reconhecem como qualidade de vida é gerada, principalmente, por emoções negativas decorrentes do sentimento de inadequação, tornando-a disfuncional em sua relação com o mundo, mesmo acreditando estar no controle dessas emoções.

No âmbito da teoria apresentada em Feist et al. (1995), de orientação Bottom-Up, que se baseia na condição de julgamento do próprio indivíduo, pelo cálculo do somatório de momentos de alegria ou sofrimento que possam produzir mudanças em sua vida, ressaltamos que, no caso dos adultos observados, essa avaliação representativa ocorre pela comparação com situações de luto ou perdas, onde o ganho acontece em permanecer estável sem a necessidade de adaptação a novas condições de vida, considerada por Diener (1996) como padrões afetivos para que o sujeito se sinta confortável.

Relacionando a condição de vida a traços da personalidade da pessoa que desenvolve um sentimento de bem-estar, estabelecendo uma disposição mais apropriada de inter-relação, observada por Seligman (2004) como inteligência social, comparada a algumas pessoas do grupo assistido, torna-se evidente quando estes, mesmo em situações como baixa escolaridade, desemprego, doença e condições mínimas de manutenção das necessidades da família, apresentam grande otimismo diante dos fatos da vida, sentindo-se gratificados por ainda estarem sujeitos a alguma mudança. Reforçando a abordagem Top-Down apresentada em Feist et al. (1995), essas pessoas possuem um comportamento racional 
diante de eventos externos baseado em sua crítica de valores, não supervalorizando situações momentâneas de dificuldade.

A generosidade, a bondade e a lealdade, citadas por Seligman (2004) como construtores cognitivos determinantes para dar qualidade à vida, são salientadas nas atividades alguns dos membros do grupo assistido, geralmente, relacionadas ao empenho religioso. Myers e Diener (1997) indicam a crença como importante aliado para a satisfação na vida, o que é visível na população assistida, que as utiliza como suporte fundamental para obter motivação no desempenho de atividades diárias. Nota-se que as pessoas buscam, além de conforto espiritual, um meio de regrar suas atitudes na incapacidade de desenvolver recursos próprios mediante situações que promovem descontrole e abusos em suas vidas, revelando a necessidade de controladores externos para manter equilíbrio justificado em circunstâncias que possam surgir. A fé aparece como manifestações secundárias, significando o meio de se alcançar condições transformadoras para a vida e nas relações pessoais, independente das práticas religiosas procuradas. Torna-se importante ressaltar que em localidades onde a população é visivelmente desfavorecida, a religiosidade é bem variada, encontrando-se desde lugares em que se praticam as crenças africanas até um número grande de igrejas ou templos evangélicos, o que revela a crescente procura por parte desta população do apoio para melhorar seu bem-estar subjetivo e encontrar as respostas para as aflições provocadas por suas experiências na vida.

Glatzer (1987) fala em satisfação modelando as emoções e Csikszentmihalyi (1992) fala na capacidade de controle da consciência organizada harmoniosamente. Contudo, se observadas algumas pessoas que tiveram sua construção cognitivo-afetiva de maneira deficiente, não recebendo recompensas externas que poderiam proporcionar bem-estar e gratificação em sua atuação, percebe-se que apresentam marcante distorção de valores morais e afetivos, refletidos em sua conduta pessoal e social, que se tornam evidentes quando, na formação de seus novos núcleos familiares, o padrão de comportamento aprendido se repete. No entanto, ocorre que no mesmo contexto pessoas que vivenciaram experiências semelhantes conseguem desenvolver, de forma criativa, atitudes positivas na condução de suas vidas ativas e que se organizam alterando comportamentos padronizados, pela capacidade de interiorizar valores que, investidos de energia psíquica, se tornam naturais em sua maneira de ser, constituindo forças que dão significado à vida.

Seligman (2004) quando fala do exercício das forças e virtudes na vida diária, acreditando serem elas responsáveis pela satisfação emocional, oferece a possibilidade do ser humano intensificar emoções através do próprio investimento para aumentar a qualidade de suas vivências. No bairro assistido, algumas pessoas se empenham em dar apoio aos membros mais carentes da comunidade, o que provoca imensa satisfação pessoal, permitindo desenvolver no indivíduo emoções positivas ao proporcionar bem-estar à outra pessoa. Em consequência destas atividades, o indivíduo adquire a capacidade de lidar com circunstâncias negativas e aprende a controlar seus pensamentos no propósito de intensificar suas emoções de forma verdadeiramente compensadora, fazendo do seu cotidiano algo significativo e gratificante.

Ao longo da vida, mudanças ocorrem de maneira natural, ocasionando perdas ou ganhos, mas pela própria condição humana o indivíduo tende a se adaptar, embora causem 
aparente desequilíbrio. Experiências como o casamento, a aquisição de bens materiais e a busca incessante pela beleza física padronizada pelos meios de comunicação provocam no indivíduo alterações consideráveis no que se relaciona ao bem-estar subjetivo, como revela Lyubomirsky (2008). De modo geral, todas as pessoas acreditam que essas novas condições de vida vão solidificando o sentimento de felicidade; no entanto, toda pessoa se adapta rapidamente a novas situações vivenciais, voltando ao nível de felicidade anterior; o indivíduo se move em direção a satisfação de um desejo e, tendo este saciado, investe sua energia na realização de um novo desejo. Nas observações feitas, verificou-se que naquelas pessoas, de menor suporte econômico, os desejos giram em torno de realizar o mínimo para a sobrevivência, sendo priorizados a moradia e o casamento, este como objetivo central para se alcançar qualidade de vida. Cabe, ainda, ressaltar que as uniões buscadas nem sempre sugerem fortes laços afetivos - são objetivos que suprem mais uma resposta social de bem-estar do que propriamente o conforto afetivo do par desejado para a condução da vida.

Embora as manifestações comportamentais sejam o veículo para a observação das representações internas de cada indivíduo, a função organizadora principal das informações interiorizadas somente se estabelece por meio da consciência, funcional para armazenamento de conteúdos internos e externos do organismo. Este aparato psíquico permite que a pessoa molde o próprio bem-estar, voltando sua atenção para eventos que proporcionaram alegrias e satisfação, da mesma forma que pode levar o sujeito a direcionar seus pensamentos para contratempos ou conflitos que enfrenta no seu cotidiano. Quando analisamos as circunstâncias vivenciadas por indivíduos que enfrentam dificuldades ao longo de sua vida, é válido salientar que, em relação a algumas pessoas, cuja atenção destaca-se na tentativa de transformar sua realidade, procurando, por exemplo, aumentar seus conhecimentos, estudando e dando prioridade ao desenvolvimento intelectual, percebe-se uma resistência por parte dos familiares que talvez considerem o esforço perda de tempo diante da realidade competitiva, desacreditando da capacidade de mudança tanto no âmbito social quanto no pessoal. Apesar dos recursos pessoais orientarem o sujeito na intenção de realizar criativamente uma nova condição de vida, ainda persiste o sentimento de inadequação social. A Psicologia sugere a visão de si mesmo através do outro, fazendo desse indivíduo incapacitado, mediante a tentativa de fazer algo diferente por si mesmo, independente de sua programação genética, como diz Csikszentmihalyi (1992), sendo o ambiente em que este sujeito está inserido o impedimento real para recriar sua vida e ter mais qualidade em suas experiências.

A qualidade de vida mencionada por Diogo, Néri e Cachioni (2004) é, na verdade, uma condição subjetiva que torna a realidade do indivíduo mais intensa, plena em satisfação, e o prepara para enfrentar sem grandes danos as contingências desagradáveis ao longo de sua existência, pois essa qualidade vem do empenho, do interesse e da dedicação do próprio sujeito quando se compromete totalmente a experimentar a vida explorando todo o seu potencial. Relacionando esta afirmativa aos membros da comunidade assistidos, surge a dificuldade de se evidenciar o que na verdade essas pessoas entendem por satisfação intensa, não apenas a conjunção carnal como determinante de felicidade, mas a capacidade de intensificar e produzir sentimentos duradouros de gratificação, elevando a autoestima e motivando-os a ter uma vida com mais alegria. A forma como estas pessoas estabelecem a 
condição para ser felizes não compreende a plenitude deste sentimento, sendo ele associado a conteúdos externos de recompensa social e material no sentido de atender apenas as condições de sobrevivência básica. De modo reparador, o lazer a que estão acostumados, como auxílio da manutenção de bem-estar, está atrelado ao desprendimento da realidade, pelo alto consumo de bebidas alcoólicas que, apesar do poder destrutivo, promove nestas pessoas o sentimento momentâneo de satisfação plena e de libertação das amarras sociais pelas quais se sentem impedidos de usufruir de uma vida com mais qualidade. Seligman (2004), quando fala que as pessoas deprimidas são mais realistas, confirma a postura adotada por indivíduos com pouca habilidade em se permitir emoções positivas, fundamentando sua construção de bem-estar subjetivo nos contingentes afetivos de sua constituição, como orientadores disfuncionais na transformação de recursos pessoais em benefício próprio.

O recurso pessoal, que seria o grande aliado no processo de construção do bem-estar subjetivo, para os indivíduos assistidos, perde força em seu propósito se consideradas as estratégias que eles acreditam ser eficientes para aumentar sua qualidade de vida. A distância da cultura impede, muitas vezes, que a seriedade dos trabalhos tenham efeito real; o vernis social inexiste e quanto mais próximos dos instintos maior a dificuldade encontrada no entendimento das questões transformadoras da reorganização da energia psíquica para investimento na própria vida. Até porque a facilidade com que estas pessoas se adaptam às adversidades contribui para a negação da possibilidade de ser alterada a sua história, no sentido de experimentar a vida com mais dignidade, alegria e realização plena, independente das circunstâncias que poderão causar perda ou sofrimento. Observase, ainda, sentimentos de incapacidade ou impotência quando questionados sobre planos e metas para o futuro, pois além de tudo o futuro ao qual é referido está intimamente ligado à condição de se visualizar em outra situação, numa vida transformada de maneira substancial e criativa - e essa projeção torna-se significativamente sem efeito.

Csikszentmihalyi (1992) considera importante a forma do indivíduo se sentir a respeito dele mesmo, sendo isto essencial para se organizar a consciência preparando-a para o processo de desenvolvimento emocional interno e, por consequência, no comportamento manifestado nas relações com o mundo. Diante disto, o indivíduo é o fator de maior importância fazendo ele mesmo uma avaliação de sua própria felicidade, pois somente com alegria e satisfação viabiliza-se a captação de sentimentos e julgamentos necessários para um sentimento geral de bem-estar. E embora na população observada existam inúmeros fatores que comprometem a formação de uma estrutura emocional do sujeito, esses dificultam, mas não impedem, que no exercício sistemático de investimento nas "pequenas alegrias" essas pessoas possam transformar sua realidade de forma a desempenhar com mais satisfação suas atividades cotidianas, desenvolvendo tanto a capacidade de equilibrar suas vivências de maneira positiva, quanto a preparação para novos recomeços, aumentando significativamente sua qualidade de vida e de bem-estar subjetivo. 
(publicações de textos, ensaios e artigos de discentes)

\section{Considerações Finais}

A literatura sobre o tema do bem-estar subjetivo aponta para a existência, em todo o processo de desenvolvimento humano, de fatores decisivos na construção do bem-estar do indivíduo, salientando os vários critérios de organização psíquica que fundamentam a questão sobre como surge a satisfação, produzida de forma objetiva na vida de cada um. Compreendendo melhor os mecanismos que possibilitam este estado, a pessoa adquire a capacidade de desenvolver e/ou intensificar emoções positivas que poderão ser importantes geradores de qualidade de vida.

Cada indivíduo é potencialmente responsável pelo próprio bem-estar na medida em que estabelece seus orientadores funcionais pela informação interpretada e armazenada na consciência de maneira singular, caracterizando a condição transformadora de recriar sua realidade, elevando sensivelmente o nível de felicidade na intenção de motivar sua entrega a vivências prazerosas do seu cotidiano. Essa construção de felicidade compreende duas possibilidades que se complementam: o bem-estar atual, que pode ser descrito como uma experiência intensa de alegria, e o bem-estar habitual que permeia várias instâncias da vida - ambas promovendo uma sensação chamada de afeto positivo. Embora seja subestimada por muitos a utilização de pequenos gestos como bondade, consideração e respeito, estes são fatores muito eficientes na produção de afetos positivos, tanto pela gratificação quanto pela aproximação, revelando a importância da atenção social na vida do sujeito.

Autores como Diener, Csikszentmihalyi e Seligman, entre outros, oferecem todo suporte para o conhecimento sobre a construção de uma vida plena em suas potencialidades e sobre o desenvolvimento de habilidades pessoais no fortalecimento de emoções que irão produzir intensa satisfação nos variados aspectos vivenciais. Uma vez que os recursos teóricos estão disponíveis, sua aplicabilidade no caso do grupo observado para a realização deste trabalho tornou-se eficaz, embora parcialmente, em função da dificuldade cultural de aceitação e entendimento por parte das pessoas observadas. Verificou-se que grande parte dessa população, que demonstra significativo sentimento de inadequação social, tende a inviabilizar a possibilidade de mudanças em suas próprias vidas impedindo o aumento de qualidade em suas experiências, tendo em vista que, nessas pessoas, o desenvolvimento da autopercepção, responsável por registrar conscientemente seus orientadores internos, se apresenta de maneira disfuncional e, assim, não estimula ativamente seus recursos físicos para elevar seu bem-estar, independentemente das circunstâncias externas.

A busca pela felicidade é uma condição natural do ser humano que ao longo da vida precisa fazer escolhas que possam conferir autonomia ao indivíduo, o que exige a responsabilidade para arcar com as consequências, ou seja, determinar as condições para sua própria felicidade. No entanto, observou-se no grupo assistido que todo o exercício que pudesse ocasionar transformações internas e produzir de maneira eficiente novas informações, sugerindo mudanças reais na vida dos sujeitos, provocava desconforto e recusa nas manifestações comportamentais dessas pessoas, talvez pela sensação de insegurança causada pela possibilidade de distanciamento do grupo padrão de identificação. Se por um lado existe no grupo observado a necessidade de realizar de forma objetiva o aumento da satisfação com a vida, trazendo bem-estar às condições do cotidiano e elevando substancialmente a qualidade de vida de cada uma daquelas pessoas, por outro 
lado ocorre, na maioria dos casos, uma "sabotagem" pessoal, provocada pela geração de conflitos, que surgem, em geral, afastando aquele indivíduo de sua realidade sóciocultural e familiar já reconhecida, na qual ele transita conformado.

Enfim, a Psicologia Positiva revela a possibilidade de se promover aumento de qualidade de vida e bem-estar subjetivo para qualquer indivíduo, mediante o exercício pessoal com o objetivo de alterar a forma de percepção e interpretação das experiências vivenciadas, de maneira que sua atuação no mundo seja embasada em emoções positivas, despertando sensações de satisfação e prazer, mesmo que as informações externas sejam negativas. Desse modo, o fortalecimento de recursos físicos torna o indivíduo capaz de realizar atividades que intensifiquem sentimentos autênticos de gratificação e estabelece a responsabilidade que cada pessoa tem de mudar a própria vida, desde que compreenda como se utiliza as informações interpretadas na condução de suas atitudes no cotidiano.

No grupo observado, ficou claro o interesse das pessoas em desenvolver recursos que proporcionem mudanças significativas em suas vidas, aumentando sua qualidade real com resultados físicos e mentais. No entanto, demonstraram ser indivíduos com grande resistência interna a mudanças que os obrigue a assumir o controle e a responsabilidade pelas experiências que vivenciam, apresentando dificuldades com a capacidade volitiva na orientação dos exercícios propostos. Parece cômoda a atitude de descartar as condições para realizar transformações; mas considerando a construção do indivíduo num contexto histórico deficiente, cabe prever a inflexibilidade desse indivíduo para novos conteúdos de aprendizagem, principalmente, quando levadas a efeito pelos afetos positivos ou negativos. Seus recursos físicos são deturpados na concepção, tornando seus valores morais e sociais muito primários; o reconhecimento das próprias emoções e sua regulação é precária, sugerindo pouca habilidade para autopercepção e identificação de satisfação plena nas experiências.

Embora sejam pessoas que busquem melhorar aparentemente suas vidas, a compreensão do que os torna mais felizes está diretamente ligada à satisfação imediata de atender necessidades básicas de sobrevivência. Essas pessoas apresentam importante dificuldade criativa, evidenciada pela incapacidade de desenvolver metas e objetivos, reforçando a maneira disfuncional de exercer atividades cognitivas que possam elevar seu bem-estar, promovendo alterações relevantes no desempenho cotidiano e nas emoções que poderão ser desencadeadas produzindo saúde física e mental, aumentando concretamente sua qualidade de vida.

Felicidade, satisfação e afeto positivo fazem parte da avaliação subjetiva de qualidade de vida. E sendo o bem-estar subjetivo definido pelas respostas emocionais diante dos fenômenos ocorridos no cotidiano, então é importante considerar que a felicidade referese ao modo como as pessoas pensam e como elas se sentem sobre suas próprias vidas, dando a elas autonomia, mas exigindo um preço, o de conhecerem a si mesmas. 
(publicações de textos, ensaios e artigos de discentes)

\section{Referências}

Baltes, P. B. (1987) Theoretical propositions of life-span developmental psychology: on the dynamics between growth and decline. Developmental Psychology, 23(5), p.611626.

Csikszentmihalyi, M. (1992) Psicologia da felicidade. São Paulo: Saraiva.

Csikszentmihalyi, M. (1999) A descoberta do fluxo. A psicologia do envolvimento com a vida cotidiana. Rio de Janeiro: Rocco.

Davidoff, L. L. (2001) Introdução à Psicologia. 3.ed. São Paulo: Makron Books.

Diener, E. (1984) Subjective well-being. Psychological Bulletin, (95), n.3, p.542-575.

Diener, E. (1996) Traits can be powerful, but are not enough: lessons from Subjective Well-Being. Journal of Research in Personality, n.30, p.389-399.

Diener, E.; Emmons, R. A. (1985) The independence of positive and negative affect. Journal of Personality and Social Psychology, v.47, n.5, p.1.105-1.117.

Diener, E.; Lucas, R. E. (1999) Personality and Subjective well-being. In: Kahneman, D.; Diener, E.; Schwarz, N. (Eds). Well-being: The foundations of hedonic psychology. New York: Russell Sage Foundation, p.213-229.

Diener, E.; Oishi, S.; Lucas, R. E. (2003) Personality, culture, and subjective well-being: Emotional and Cognitive Evaluation of Life. Annual Review of Psychology, 54, Academic Research Library, p. 403-425.

Diener, E.; Seligman, M. E. P. (2004) Beyond money: toward an economy of well-being. Psychological Science in the Public Interest, 5, 1-31.

Diener, E.; Suh, E.; Oishi, S. (1997) Recent findings on subjective well-being. Indian Journal of Clinical Psychology, 24, 25-41.

Diogo, M. J. D.; Néri, A. L.; Cachioni, M. (Orgs.) (2004) Saúde e qualidade de vida na velhice. 2.ed. Campinas: Alínea. Coleção Velhice e Sociedade.

Feist, G. F. et al. (1995) Integrating top-down and bottom-up structural models of Subjective Well-Being: a longitudinal investigation. Journal of Personality and Social Psychology, v.68, n.1, p.138-150.

Freud, S. (1974) Algumas lições elementares de psicanálise. (1940/1938) In: Edição Standard Brasileira das Obras Psicológicas Completas de Sigmund Freud. Rio de Janeiro: Imago. vol. XXIII.

Glatzer, W. (1987) Subjective Well-Being: components of well-being. Social Indicators Research, n.19, p.25-38.

Larson, R. W. (1987) On the independence of positive and negative affect within hour to-hour experience. Motivation and Emotion, v.11, n.2, p.145-156.

Larson, R. W. (2000). Toward a psychology of positive youth development. American Psychologist, 55, 170-183.

Lyubomirsky, S. (2008) A ciência da felicidade: Como atingir a felicidade real e duradoura. Rio de Janeiro: Elsevier. 
Michalos, A. C. (1980) Satisfaction and happiness. Social Indicators Research, n.20, p.355-381.

Myers, D. G.; Diener, E. (1997) The science of happiness. The Futurist, Washington, Sep/ Oct, v.31, n.5, p.S1-S7.

Ryff, C. D. (1989) Happiness is everything or is it? Explorations on the meaning of Psychological Well-Being. Journal of Personality and Social Psychology, v.57, n.6, p.1.069-1.081.

Ryff, C. D.; Keyes, C. L. M. (1995). The structure of psychological well-being revisited. Journal of Personality and Social Psychology, 69, 719-727.

Seligman, M. E. P. (2004) Felicidade autêntica: Usando a nova Psicologia Positiva para a realização permanente. Rio de Janeiro: Objetiva.

Seligman, M. E. P. (2008) Positive health. Applied Psychology, v.57, Issue Supplement s1, p.3-18, July.

Seligman, M. E. P.; Csikszentmihalyi, M. (2000) Positive psychology: an introduction. American Psychologist, 55, 5-14.

Suh, E.; Diener, E.; Fujita, F. (1996) Events and subjective well-being: only recent events matter. Journal of Personality and Social Psychology, 70(5), p.1091-1102.

Wong, P. T. (1989) Personal meaning and successful aging. Canadian Psychology, 30(3), p.516-525. 